\title{
Using the Life-Cycle Paradigm to Support Factory Planning Approaches
}

\author{
Roberto da Piedade Francisco, João Bastos, and Américo Azevedo \\ INESC Porto \& Faculdade de Engenharia da Universidade do Porto, \\ Rua Dr. Roberto Frias S/N \\ 4200-465 Porto, Portugal \\ \{roberto.piedade, joao.bastos, ala\}@fe.up.pt
}

\begin{abstract}
In order to fulfill all challenges related to design, management, evaluation and reconfiguration of new or existing facilities, the development of a new, integrated and holistic factory framework is required. In this context, a new requirements model is proposed in the context of the innovative framework called Virtual Factory Framework. Using this approach in factory planning it is expected to improve the ability to generate better and more sustainable solutions over the entire factory life-cycle. This paper underlines the use of the lifecycle paradigm in order to enable the future factory planning approaches.
\end{abstract}

Keywords: Factory Planning, Virtual Factory Framework, Life-Cycle Paradigm.

\section{Introduction}

The Virtual Factory Framework is a new foresight to the Next Generation Factory, viewing the factory as a new and complex type of product. It is appropriate to consider factories as long life and complex products, since they have to follow the same steps in its origin as products. They also have to be permanently adapted to the needs and requirements of markets and economic efficiency, applying the life-cycle paradigm to the factory as a product [1].

The new line of thought in manufacturing management is directed to the optimization and value creation of products, processes and technologies throughout the factory life-cycle. The main objectives are to improve the effective use of the decreasing time available to reach the market and the increasing need to reduce design, implementation and production costs.

The present work addresses state of the art concepts and research issues in the context of an RTD European project entitled "Holistic, extensible, scalable and standard Virtual Factory Framework", namely in the topic of factory planning and the concept of "factory as a product".

This document is organized as follows: the second section presents the next generation factory concepts; the third section presents two contemporary factory planning approaches; the fourth section addresses the virtual factory framework and the supporting requirements model; and finally, the conclusions and further works are presented in the last section. 


\section{Next Generation Factory Concepts}

In a factory development project, the factory can be seen as a product that requires a complex life-cycle and the use of techniques already used for product development. This new paradigm can be introduced to support manufacturers in the creation of value through new solutions (products, processes and technology) that improve quality, reduce ramp-up and product delivery time, and also reduce production costs in order to achieve greater competitiveness. Some initiatives have been developed in order to reach these objectives. One of the most recent and robust is ManuFuture [2]. This initiative aims to promote investments in innovation that will ensure the future of European industry in a knowledge-based economy. At the same time, its aim is to speed up the rate of industrial transformation in Europe, providing High-AddingValue employment and reaching a major share of the world's manufacturing output in the future knowledge-driven economy, seeking to achieve Competitive Sustainable Manufacturing [2].

Every factory and production facility is a distinctive entity. Each factory is different in terms of its products, processes, layout, structure, human resources and corporate philosophy. However, the common denominator for them to guarantee their survival is to make production facilities adaptable. The adaptability is becoming a top priority for modern enterprises and is a continuous task for management.

Modern factories have to be modular, scalable, flexible, open, agile and knowledge-based in order to be able to adapt, in real time, to the continuously changing market demands, technology options and government regulations.

In a manufacturing company, the job of a production facility is to perform competitively on the market, with high levels of adaptability, by producing (material) goods as products in line, as much as possible, with the market demand. In order to achieve this adaptability, its companies need to have an integrated perspective. The interrelationship between the products, processes and factory thus requires that the different actors are highly involved and interdependent (Figure 1). The product required by the market determines the process characteristics and configuration, such as equipment, organization and product volume and mix. The process determines the plant with the equipment, support facilities and services that individuals operate, control and supervise. And finally the factory determines the product volume, mix and cadence. Changing one component causes other components to change as well. This cannot only be applied to production facilities, but also to an entire factory [3].

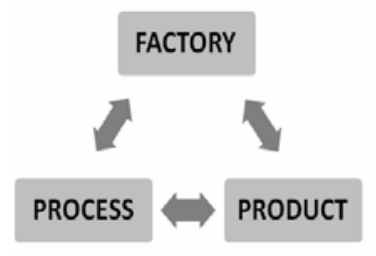

Fig. 1. Interdependence between product, production process and factory plan 
One of the factors that have a profound impact on adaptability is flexibility. Hence the constant need to strengthen and improve flexibility in the design of production processes and factory planning. Thus, the need for new methodologies that support the design of the factory as a product is increasingly obvious. But, since this is a highly complex task, it is necessary to study and analyze the approaches followed by experts and experienced implementers in the field.

A first notion that must be present at this stage is the fact that the design of the factory cannot be separated from the planning process and product design, particularly due functional interdependencies and due to the similarity and parallelism observed in their life-cycle, as represented in Figure 2.
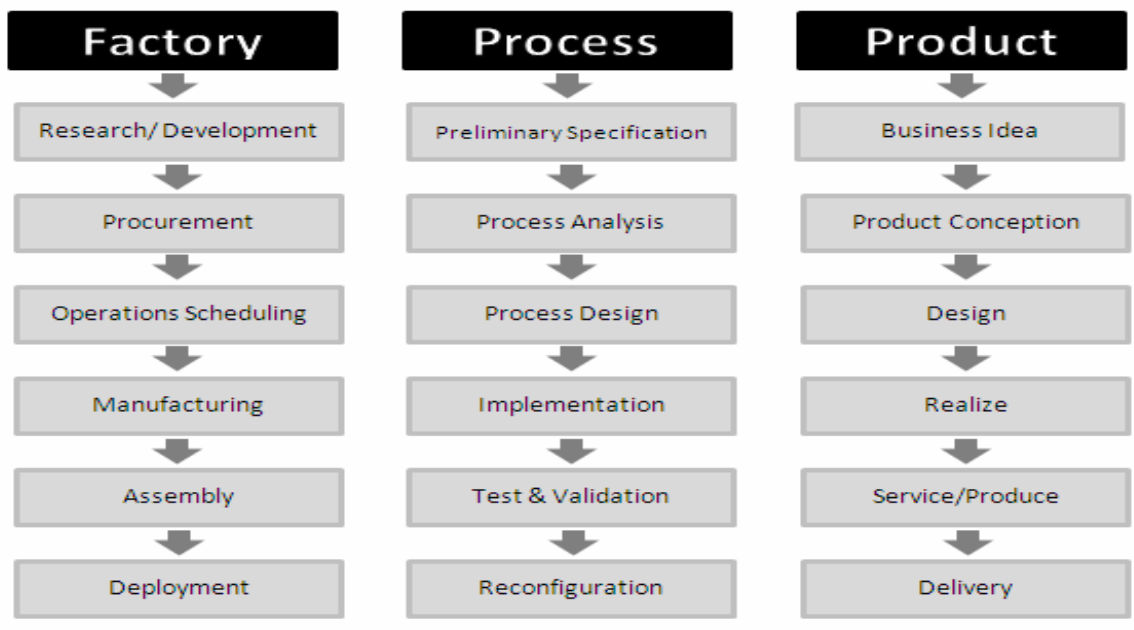

Fig. 2. Factory, process and product life-cycle

Indeed, the benefits of applying this concept are feasible and desirable if a factory planning can be carried out using knowledge on life-cycle paradigm, process planning, factory planning and new product development (NPD).

The product life-cycle is the time period between the moment that the product is conceived (concept, plan, design, idea, notion, or thought) and when its production is no longer profitable [4]. This is a paradigm that can properly conduct the phases of product management through the concepts and tools applied in product development. Then, when taking the concept of the factory as a product, it can also extend the paradigm to this new perspective.

The product life-cycle phases can be studied in different organizational areas such as: marketing, product management, manufacturing and computer systems. For instance, the concept of PLM (Product Lifecycle Management) has to do with the management of activities and product requirements from the viewpoint of processes development, manufacturing and product utilization in the context of data management, while the traditional concept of product life-cycle applies to product marketing and service life [5]. Although the PLM is currently presented as software, in fact, it is a methodology supported in an integrated set of software tools oriented to life-cycle 
management that is used to manage specific tasks and to plan the entire process of product management.

In fact, the life-cycle paradigm can be applied in order to harmonize and integrate the life-cycle of the product and factory (manufacturing view) simultaneously, providing the idealization of its phases, as shown in Figure 3.

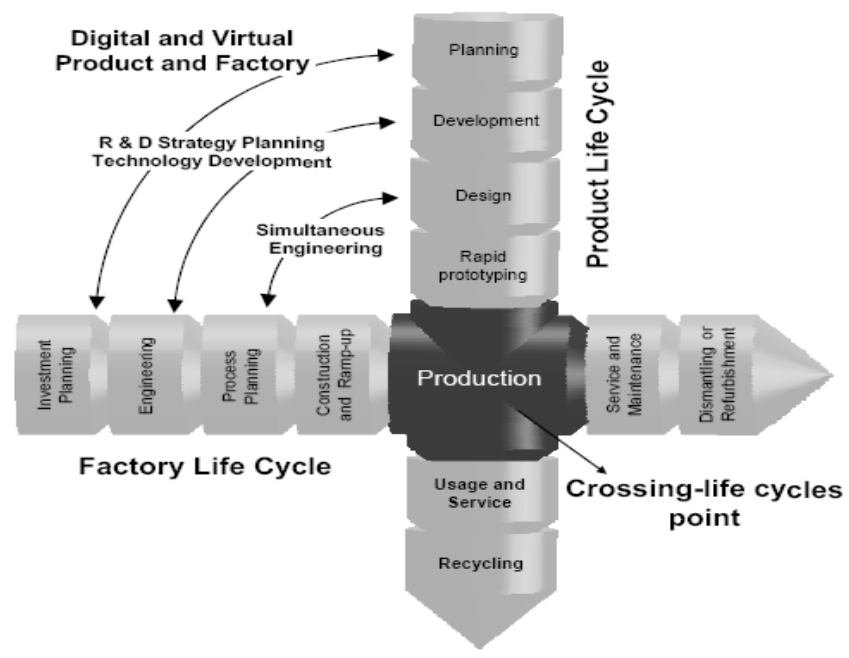

Fig. 3. Factory life-cycle crossing product life-cycle [6]

This approach intends to set up a foundation for factory planning in order to establish the phases that can be standardized in the context of factory design. This harmonization approach of the converging life-cycles makes it possible to use simulations in the design of an object-oriented collaborative product, starting at the vision of the virtual factory to the real factory at the intersection so-called "Crossing-life-cycles point" [6].

According to this idea, we will now present some methodologies followed in Factory Planning and Product Life-Cycle mentioned in the literature.

\section{Factory Planning Approaches}

In the context of the project research, it was possible to identify several factory planning approaches. The next paragraphs present a brief overview of two of them which have presented relevant contributions for the Virtual Factory Framework requirements definition on the factory design phase.

Systematic and Situation-driven Planning Methods [3] - Planning production facilities means envisioning several aspects that includes the products that are going to be produced, the processes required to produce them and the physical infrastructure required to the production. This approach requires the use of methodologies that efficiently design the planning process. According to Schenk [3], a planning project can 
be developed systematically and/or situation-driven on the basis of various planning process and procedural model views.

A systematic, methodical approach is influenced by situation-driven decisions. It serves the development of a planning project through internal and external planning activities on the basis of various planning process and procedural model views. These production facility and factory lifecycle design planning phases and stages are represented in figure 4 .

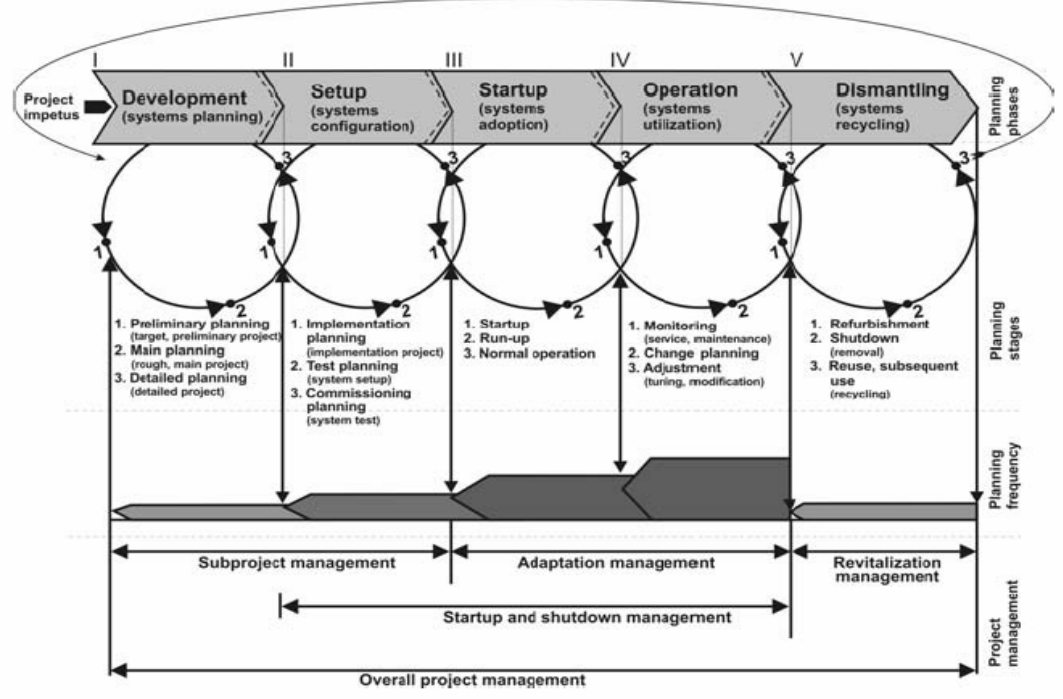

Fig. 4. Production facility and factory lifecycle design planning phases [3]

The planning activities span a production facility's entire life-cycle from development/planning through setup, execution and operation to phase-out [3].

Therefore, the Systematic Planning Processes have the following steps:

1. Rough sequence of processes and manufacturing plants planning

2. The project design takes place with the following sequence:

a) Main process (parts manufacturing or assembly)

b) Main process storage; main process transports system; production process control; quality assurance; fixtures tools and testing equipment;

c) Manufacturing equipment engineering; maintenance; auxiliary materials storage; power conversion equipment; waste treatment facilities,

d) Management; power generation; social, medical and sanitary facilities.

3. Complex planning model - this consists of the following planning complexes:

a) Project definition

b) Project development

c) Project implementation 
An enhancement of the systematic approach is the situation-driven method for factory planning also presented by Schenk et al. [3]. The situation-driven planning differs from the systematic planning in that, as a result of operational decisions (e.g. changes in target, data, product, technology, requirement, time, profitability or quality specifications), all or part of the planning process and sequences have to be changed.

According to this situation-driven approach the planning model acquires reactivity and is adaptable to operational changes. Its redevelopment is based on the current situation and uses selected systematic planning components and activities to ensure the accomplishment of the goals.

Factory planning supported in simulation tools - Simulation tools are popular in various industrial fields as decision support systems. Since factory planning is one of the most complex tasks, the need of decision support tools was especially comprehensible. Several commercial solutions have been appearing in the last decade to the market as appropriate to deal with the problem of factory planning.

Mertins et al. [7] presents a scalable, flexible and adaptive simulation model used in factory planning based on existing ERP (Enterprise Resource Planning) and MES (Manufacturing Execution System) data. The objective of this work is to enable an industrial engineer without simulation expertise to perform the simulations that are necessary to support several tasks including process planning and factory planning. Moreover, the simulation model facilitates an analysis of the results for different scenarios, using the actual data from the ERP and MES systems.

In their research, Wenbin et al. [8] report a development in a production engineering-oriented virtual factory - a planning cell-based manufacturing systems design approach. This manufacturing systems design process is based on a planning cell reengineered according to the concept of concurrent engineering. The process modeling of a production engineering-oriented virtual factory is proposed at both generic and detailed levels. With logic level simulation (discrete event simulation, etc.) and physical level simulation (ergonomics simulation, immersed virtual reality, etc.), a distributed, layered and integrated simulation model can be used to build a virtual factory environment for concurrent manufacturing systems design during the whole lifecycle of production engineering, including production system configuration, factory layout, and so on. Therefore, the designed manufacturing systems can be evaluated and optimized before their implementation.

Once the planning methodologies and the life-cycle paradigm are presented, the next step is based on the development of a conceptual model to support the design of the new generation factories - the Virtual Factory Framework.

\section{Virtual Factory Framework}

\subsection{Framework Overview}

In the virtual factory context, the manufacturing attributes are migrating to other forms which include concerns on how to solve highly complex tasks under increasing demand for adaptability, cost, efficiency, durability, reliability, scalability and security 
[6]. Thus, the aim of designing the future factories is accomplished if the process planning in a virtual factory can be synchronized with the real factory through basic components that can be simulated by aligning the factory design and decision-making process during the factory life-cycle.

A virtual factory can build designs of manufactured components (geometric models) and their respective process plans to make it possible for any manufacturing process to be defined, modeled and implemented.

So, this work is being developed within the authors' contribution for the Project VFF - "Holistic, extensible, scalable and standard Virtual Factory Framework", a European collaborative project supported by the European Commission that includes about thirty partners from several European companies, universities and research centers. The project's goal is to define the next generation of Virtual Factory Framework, encouraging the European industry to improve its knowledge in terms of design, management, evaluation and reconfiguration of new or existing facilities. At the same time, it seeks to promote major time and costs savings, supporting the capability to simulate the dynamic complex behavior over the entire life-cycle factory interpreted as a complex long living product that synchronize the Virtual Factory with the Real Factory.

\subsection{VFF Requirement Analysis for Factory Design}

The first task to building up a framework that supports virtual factory relies on extensive requirements analysis of the real factory environment model. The present work have identified four main requirements blocks for the entire factory life-cycle characterization: Strategic Planning, Facility Planning, Process Planning and Factory Operation (Figure 5).

On each requirement's blocks there are subsets of requirements which deal with the main functionalities required in the design, management, evaluation and reconfiguration of new or existing facilities. As an example: the building requirements in the Facility Planning block comprises: Economic requirements (operation and maintenance costs; low energy costs, flexibility, operating supply materials, etc.); Sustainability requirements (emissions, reusability, reutilization, etc.); Location requirements (building plot, logistic connections, accessibilities, etc.); Layout requirements (optimal room geometry, utilities integration, modifiable structure configuration, etc.); Technological requirements (technological, changeability, capacity feasibility, ergonomics, etc.); Protection requirements (health and safety norms, supply protection, materials handling, etc.); General requirements (structural integration, optimal infrastructure, architecture, etc).

With this approach, it can be considered that the requirements blocks are iteratively adapted during the factory life-cycle in order to cope with the real changing environment. On each block construction, for each factory instantiation, there are constraints which are propagated to the next block of requirements. In fact, it intends to achieve a "continuous performance improvement" through a reference model fine-tuning for each cycle of iteration. 


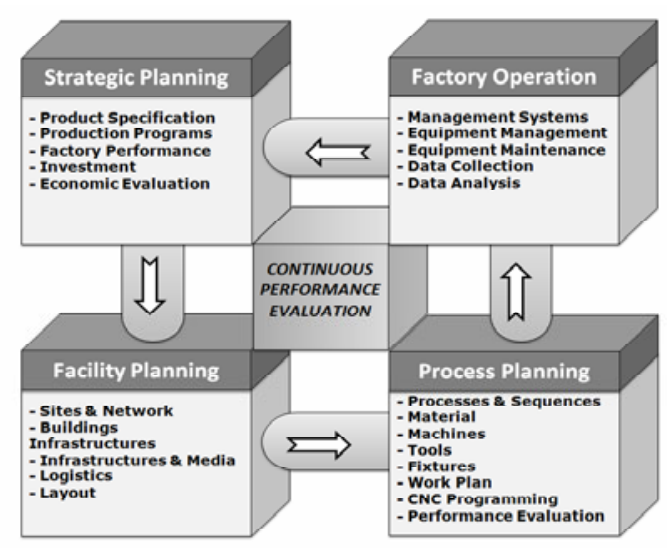

Fig. 5. VFF main requirements blocks

\section{Conclusions and Further Work}

This paper addresses the problem of factory planning during the entire factory lifecycle through a holistic, extensible, scalable and standardized virtual factory framework. It presents also some of the available methodologies for factory planning and how it can be integrated with the paradigm of product life-cycle.

The challenge of factory design derives from the interdependence between the factory planning, process planning and product development. Since this is a complex task with implications in a large number of functions and stakeholders, as well as time constraints, there is a need for a support framework. This need impelled a new area of research, with the involvement of academic and industry partners, aiming to develop a new generation virtual factory framework that will meet the challenges of integration, flexibility and sustainability of designing the next generation factories.

Finally, this paper addressed the requirements conceptual model within the Virtual Factory Framework project by presenting a set of requirements obtained in a short example.

The ongoing VFF project aims to provide the industrial managers with a more powerful toolset to support the decision making during the entire factory life-cycle. Any future work foreseen in this project involves development and implementation of the VFF framework with factories templates on several industrial scenarios.

\section{References}

1. VFF Consortium. Holistic, extensible, scalable and standard Virtual Factory Framework, FP7-NMP-2008-3.4-1 (2009)

2. Jovane, F., Westkamper, E., Williams, D.: The ManuFuture Road: Towards Competitive and Sustainable High-Adding-Value. Springer, Berlin (2009)

3. Schenk, M., Wirth, S., Muller, E.: Factory Planning Manual, 1 ed. Springer, Berlin (2010) 
4. Mital, A., Desai, A., Subramanian, A., Mital, A.: Product Development: A Structured Approach to Consumer Product Development, Design and Manufacture. Elsevier, Amsterdam (2008)

5. Saaksvuori, A., Immonen, A.: Product Lifecycle Management. Springer, Berlin (2005)

6. Pedrazzoli, P., Bathelt, J., Chryssolouris, G., Rovere, D., Pappas, M., Boër, C.R., Constantinescu, C., Dépincé, P., Westkämper, E.: High Value Adding VR Tools for Networked Customer-Driven Factory. In: Proceedings of the Digital Enterprise Technology (2007)

7. Mertins, K., Rabe, M., Gocev, P.: Integration of Factory Planning and ERP/MES Systems: Adaptive Simulation Models. In: Lean Business Systems and Beyond. Springer, Boston (2008)

8. Wenbin, Z., Juanqi, Y., Dengzhe, M., Ye, J., Xiumin, F.: Production Engineering-Oriented Virtual Factory: A Planning Cell-Approach to Manufacturing Systems Design. International Journal of Advanced Manufacturing Technology (2006) 